\title{
Risk factors associated with short-term complications and mortality after pediatric spinal arthrodesis
}

\author{
Nancy Abu-Bonsrah, MD, ${ }^{1}$ C. Rory Goodwin, MD, PhD,,2 Gezzer Ortega, MD, MPH, ${ }^{3}$ \\ Fizan Abdullah, MD, PhD, ${ }^{4}$ Edward Cornwell, MD, ${ }^{3}$ Rafael De la Garza-Ramos, MD, ${ }^{1}$ \\ Mari L. Groves, MD, ${ }^{1}$ Michael Ain, MD, ${ }^{5}$ Paul D. Sponseller, MD, ${ }^{5}$ and Daniel M. Sciubba, MD ${ }^{1}$ \\ Departments of ${ }^{1}$ Neurosurgery and ${ }^{5}$ Orthopedic Surgery, The Johns Hopkins University School of Medicine, Baltimore, Maryland; \\ ${ }^{2}$ Department of Neurosurgery, Duke University Medical Center, Durham, North Carolina; ${ }^{3}$ Department of Surgery, Howard \\ University School of Medicine, Washington, DC; and ${ }^{4}$ Department of Pediatric Surgery, Northwestern University Feinberg School \\ of Medicine, Chicago, Illinois
}

OBJECTIVE Spinal arthrodesis is routinely performed in the pediatric population. However, there is limited information on the short-term outcomes of pediatric patients who have undergone spine fusion. Thus, the authors conducted a retrospective review of the Pediatric National Surgical Quality Improvement Program (NSQIP) database to determine the short-term mortality, complication, reoperation, and readmission rates of pediatric patients who underwent spinal arthrodesis for all indications.

METHODS The Pediatric NSQIP database was queried for all patients who underwent spinal arthrodesis between 2012 and 2014. Patient demographics, comorbidities, body mass index, American Society of Anesthesiologists classification, and operative time were abstracted. Short-term mortality, reoperation, and readmission rates and complications were also noted. Univariate and multivariate analyses were performed to delineate patient risk factors that influence shortterm mortality, complications, reoperation, and readmission rates.

RESULTS A total of 4420 pediatric patients who underwent spinal fusion were identified. Common indications for surgical intervention included acquired/idiopathic scoliosis or kyphoscoliosis (71.2\%) and genetic/syndromic scoliosis (10.7\%). The mean patient age was $13.7 \pm 2.9$ years, and $70 \%$ of patients were female. The overall 30 -day mortality was $0.14 \%$. Multivariate analysis showed that female sex and pulmonary comorbidities significantly increased the odds of reoperation, with odds ratios of 1.43 and 1.78 , respectively.

CONCLUSIONS In the NSQIP database for pediatric patients undergoing spinal arthrodesis for all causes, there was a $3.6 \%$ unplanned reoperation rate, a $3.96 \%$ unplanned readmission rate, and a $9.0 \%$ complication rate. This analysis provides data for risk stratification of pediatric patients undergoing spinal arthrodesis, allowing for optimized care.

https://thejns.org/doi/abs/10.3171/2017.7.FOCUS17313

KEY WORDS pediatric; spine; arthrodesis; fusion; short-term outcomes; mortality; reoperation; readmission; complications; NSQIP

$\mathrm{S}$ PINAL arthrodesis is commonly performed in the pediatric population for a number of indications, including pediatric deformity, trauma, and tumorinduced instability. $1,2,5,7,10,13,14,16,17,23-25$ Patients undergoing spinal arthrodesis are at significant risk for developing complications and having unplanned readmissions and/ or reoperations. These clinical outcomes are undesirable for patients, physicians, and the health care system in gen- eral, as they can result in increased cost and decreased quality of life. Greater understanding of the risk factors associated with adverse outcomes is needed to more effectively stratify patient populations, identify high-risk groups, and ultimately decrease operative risk. Multiple studies have examined each of these factors in subsets of pediatric patients undergoing spinal fusion. The majority of analyses focus on either one particular population of

ABBREVIATIONS ACS = American College of Surgeons; ASA = American Society of Anesthesiologists; BMI = body mass index; NSQIP = National Surgical Quality Improvement Program; SSI = surgical site infection; UTI = urinary tract infection.

SUBMITTED May 29, 2017. ACCEPTED July 17, 2017.

INCLUDE WHEN CITING DOI: 10.3171/2017.7.FOCUS17313. 
TABLE 1. Patient preoperative and intraoperative characteristics

\begin{tabular}{|c|c|}
\hline Characteristic & Value \\
\hline Mean age $\pm S D$, yrs & $13.7 \pm 2.9$ \\
\hline \multicolumn{2}{|l|}{ Sex } \\
\hline Female & $3087(69.8)$ \\
\hline Male & $1333(30.2)$ \\
\hline \multicolumn{2}{|l|}{ Ethnicity } \\
\hline White & $2947(66.7)$ \\
\hline Black & $663(15)$ \\
\hline Hispanic & $199(4.5)$ \\
\hline Asian & $102(2.3)$ \\
\hline American Indian or Alaskan Native & $22(0.5)$ \\
\hline \multicolumn{2}{|l|}{$\mathrm{BMI}^{*}$} \\
\hline Underweight/normal & $19(0.4)$ \\
\hline Overweight & $29(0.7)$ \\
\hline Obese & $4361(98.7)$ \\
\hline Steroid use w/in 30 days & $58(1.3)$ \\
\hline Prior op w/in 30 days & $53(1.2)$ \\
\hline Blood transfusion w/in $48 \mathrm{hrs}$ prior to op & $127(2.9)$ \\
\hline Inotropic support at time of op & $165(3.7)$ \\
\hline \multicolumn{2}{|l|}{ Wound classification } \\
\hline Clean & $4382(99.1)$ \\
\hline Clean/contaminated & $28(0.63)$ \\
\hline Contaminated & $5(0.11)$ \\
\hline Dirty/infected & $5(0.11)$ \\
\hline \multicolumn{2}{|l|}{ Operative characteristics } \\
\hline \multicolumn{2}{|l|}{ ASA classification } \\
\hline$|-| \mid$ & $2933(66.4)$ \\
\hline$\geq|I|$ & $1478(33.4)$ \\
\hline Unassigned & $9(0.2)$ \\
\hline Mean op time $\pm S D$, mins & $296.5 \pm 117.1$ \\
\hline Mean anesthesia time \pm SD, mins & $404.6 \pm 131.9$ \\
\hline \multicolumn{2}{|l|}{ Diagnosis } \\
\hline $\begin{array}{l}\text { Adolescent idiopathic/acquired scoliosis \&/or } \\
\text { kyphoscoliosis }\end{array}$ & $3150(71.3)$ \\
\hline Genetic \& syndromic scoliosis & $471(10.7)$ \\
\hline $\begin{array}{l}\text { Congenital/acquired deformity of the spine } \\
\text { (not kyphosis, scoliosis, or lordosis) }\end{array}$ & $256(5.8)$ \\
\hline $\begin{array}{l}\text { Neuromuscular disorders other than cerebral } \\
\text { palsy }\end{array}$ & $134(3.0)$ \\
\hline Abnormalities of the bone/cartilage & $90(2.0)$ \\
\hline $\begin{array}{l}\text { Congenital diplegia/hemiplegia/quadriplegia/ } \\
\text { paraplegia }\end{array}$ & $86(1.9)$ \\
\hline Spondylolisthesis/spondylosis & $47(1.1)$ \\
\hline Cerebral palsy & $20(0.45)$ \\
\hline Lordosis & $11(0.25)$ \\
\hline Tumor & $8(0.18)$ \\
\hline Inflammatory/infectious & $6(0.14)$ \\
\hline
\end{tabular}

Values are presented as the number of patients (\%) unless stated otherwise.

* Available for 4409 patients.

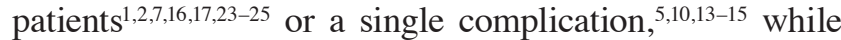
others have been limited to single centers ${ }^{5,7,9,10}$ or to the adult population. ${ }^{7,18,20,21}$ Few studies have provided a comprehensive description of patient characteristics, operative factors, and comorbidities on short-term morbidity and mortality after spinal arthrodesis in children. ${ }^{6}$ With an increasing number of procedures being performed in the United States, further characterization of the short-term outcomes of patients undergoing spinal arthrodesis in the pediatric population is warranted.

The American College of Surgeons National Surgical Quality Improvement Program (ACS NSQIP) is a multicenter pediatric database that aims to collect short-term data on pediatric patients undergoing a wide array of procedures for all indications. This database was used to determine clinical outcomes in pediatric patients undergoing spinal arthrodesis. Our objectives were to 1) analyze the short-term mortality rate, complications, reoperation rates, and readmission rates; and 2) identify significant patient risk factors for short-term mortality rate, complications, reoperation rates, and readmission rates. Information from this analysis may bolster continued initiatives to optimize patient care by allowing health care teams to more effectively stratify preoperative risk and counsel patients and their families.

\section{Methods}

\section{Patient Selection From NSQIP Database}

Pediatric patients $(<18$ years) who underwent spinal arthrodesis during the years 2012-2014 were identified from the ACS NSQIP pediatrics database using specified Current Procedural Terminology codes $(22800$, 22802, 22804, 22840, 22842, 22843, 22844). The methodology and characteristics of the database have been previously described. ${ }^{20,21}$ Patient demographics, including age, sex, race, American Society of Anesthesiologists (ASA) classification, body mass index (BMI), comorbidities, and preoperative serum albumin, were abstracted for analysis. The spinal arthrodesis procedure performed, operative time, 30-day mortality, and postoperative complications were also included.

\section{Statistical Analysis}

The primary outcome measures were short-term mortality rate and complications. Secondary outcomes were reoperation and readmission rates. A descriptive analysis was performed detailing the short-term mortality rate, complications, reoperation rates, and readmission rates in patients who underwent the procedures corresponding to the specified Current Procedural Terminology codes. Subsequent univariate and multivariate analyses were done to delineate patient risk factors that influence short-term mortality, complications, reoperation rates, and readmission rates. The multivariate analysis was performed using multivariate logistic regression models adjusting for age, sex, race/ethnicity, comorbidities, BMI, ASA classification, arthrodesis procedure, operative time, blood loss, readmission, infection, reoperation, instrumentation failure, or other complication. A p value $<0.05$ was considered statistically significant. 
TABLE 2. Incidence of mortality and complications

\begin{tabular}{lc}
\hline \multicolumn{1}{c}{ Characteristic } & No. of Patients $(\%)$ \\
\hline Short-term mortality & $6(0.14)$ \\
\hline Unplanned reop & $159(3.6)$ \\
\hline Still admitted $>30$ days & $25(0.37)$ \\
\hline Unplanned readmission & $175(3.96)$ \\
\hline Bleeding/transfusion & $2969(67.2)$ \\
\hline Complications & $398(9.0)$ \\
\hline
\end{tabular}

\section{Results}

\section{Patient Demographics and Preoperative Characteristics}

Between 2012 and 2014, 4420 pediatric patients in the NSQIP database underwent spinal arthrodesis. The mean patient age was $13.7 \pm 2.9$ years, and approximately $70 \%$ were female. The majority of patients $(66.7 \%)$ were white, and $15 \%$ were black. Overall, $1.3 \%$ of the patients received steroids within 30 days of their spinal arthrodesis procedure, while 53 patients (1.2\%) had undergone a prior operation within 30 days of the fusion. Blood transfusions were performed in $2.9 \%$ of patients within 48 hours prior to the surgery, and $3.7 \%$ of them had inotropic support at the time of surgery (Table 1). Preoperative albumin levels were available for 1318 patients (30\%), and of those patients, $97 \%$ had values $\geq 3.6 \mathrm{~g} / \mathrm{dl}$.

\section{Operative Characteristics}

Adolescent idiopathic/acquired scoliosis and/or kyphoscoliosis were the most common indications for spinal arthrodesis, representing $71.2 \%$ of the patient population. Genetic/syndromic scoliosis was the primary diagnosis in $10.7 \%$ of cases; $5.8 \%$ of patients had congenital/acquired deformity of the spine other than kyphosis, scoliosis, or lordosis (i.e., fusion of the vertebrae, hemivertebrae, or absence of a vertebrae, among others); $3 \%$ had a primary diagnosis of neuromuscular disorders other than cerebral palsy; and 2\% had abnormalities of the bone or cartilage. Tumor and trauma as indications for surgery represented a minority of the patients, accounting for $0.18 \%$ and $0.11 \%$, respectively (Table 1). Other operative indications are also presented in Table 1. A significant number of cases were elective; $66 \%$ of patients had an ASA classification $\leq$ II. Patients' wounds were classified as clean in the majority of patients (Table 1). The mean operative time was 296.5 \pm 117.1 minutes, with a mean anesthesia time of $404.6 \pm$ 131.9 minutes.

\section{Postoperative Outcome}

The short-term mortality rate was $0.14 \%, 3.6 \%$ of the patients underwent unplanned reoperations within the 30day period, and $3.96 \%$ had unplanned readmissions. A bleeding or transfusion event was documented in $67.2 \%$ of the patients, and a significant number of patients $(9.0 \%)$ sustained a variety of complications (Table 2). Surgical site infections (SSIs) complicated a number of cases, with $1 \%$ of patients having superficial SSIs, $1.1 \%$ having deep incisional SSIs, $0.27 \%$ sustaining organ/space SSI, and $0.84 \%$ having wound disruption. Pneumonia occurred in
TABLE 3. Incidence of complications

\begin{tabular}{lc}
\hline \multicolumn{1}{c}{ Complication } & No. of Patients (\%) \\
\hline Superficial SSI & $44(1.0)$ \\
\hline Deep incisional SSI & $48(1.1)$ \\
\hline Organ/space SSI & $12(0.27)$ \\
\hline Wound disruption & $37(0.84)$ \\
\hline Pneumonia & $61(1.4)$ \\
\hline Unplanned intubation & $60(1.4)$ \\
\hline Pulmonary embolism & $1(0.02)$ \\
\hline Progressive renal insufficiency & $6(0.14)$ \\
\hline Acute renal failure & $3(0.07)$ \\
\hline UTI & $51(1.2)$ \\
\hline Coma >24 hrs & $1(0.02)$ \\
\hline Stroke & $2(0.05)$ \\
\hline Seizure & $2(0.05)$ \\
\hline Nerve injury & $16(0.36)$ \\
\hline Cardiac arrest requiring CPR & $8(0.18)$ \\
\hline Graft/prosthetic/flap failure & $2(0.05)$ \\
\hline VT requiring therapy & $5(0.11)$ \\
\hline Systemic sepsis & $36(0.81)$ \\
\hline Central-line associated bloodstream infection & $3(0.007)$ \\
\hline
\end{tabular}

$\mathrm{CPR}=$ cardiopulmonary resuscitation; $\mathrm{VT}$ = venous thromboembolism.

$1.4 \%$ of patients, another $1.4 \%$ had an unplanned intubation, and $1.2 \%$ had a UTI. The incidence of complications, including SSI, seizure, stroke, nerve injury, and thromboembolic events, among others, is reported in Table 3.

Of the unplanned readmissions $(\mathrm{n}=134)$ with an indicated reason, deep incisional SSI, wound disruption, superficial SSI, and organ/space SSI were the most common, representing $25.4 \%, 19.4 \%, 10.4 \%$, and $3.7 \%$, respectively (Fig. 1). Reoperations were frequently performed for complex wound infections (13.8\%), incision and drainage of a deep abscess (18.7\%), hematoma/seroma fluid collection (8.2\%), reinsertion of a spinal fixation device (6.9\%), and posterior arthrodesis $(6.9 \%)$. Reoperation indications and procedures are presented in Table 4.

\section{Univariate and Multivariate Analyses of Risk Factors for Reoperation}

Univariate analysis revealed a number of significant risk factors $(\mathrm{p}<0.05)$ for reoperation, including pulmonary comorbidities (ventilator dependence, pneumonia, oxygen support, and structural pulmonary/airway abnormality), esophageal/gastric/intestinal disease, CNS conditions (cerebrovascular accident/stroke or traumatic/ acquired brain injury with resulting neurological deficit, developmental delay/impaired cognitive status, seizure disorder, cerebral palsy, structural CNS abnormality, and intraventricular hemorrhage), neuromuscular disorder, nutritional support, blood transfusion, acute renal failure, and wound complications (including open wounds, superficial SSI, deep incisional SSI, organ/space SSI, and wound disruption) (Table 5).

Multivariate analysis revealed only 2 characteristics as significant risk factors $(\mathrm{p}<0.05)$ for reoperations, namely, 


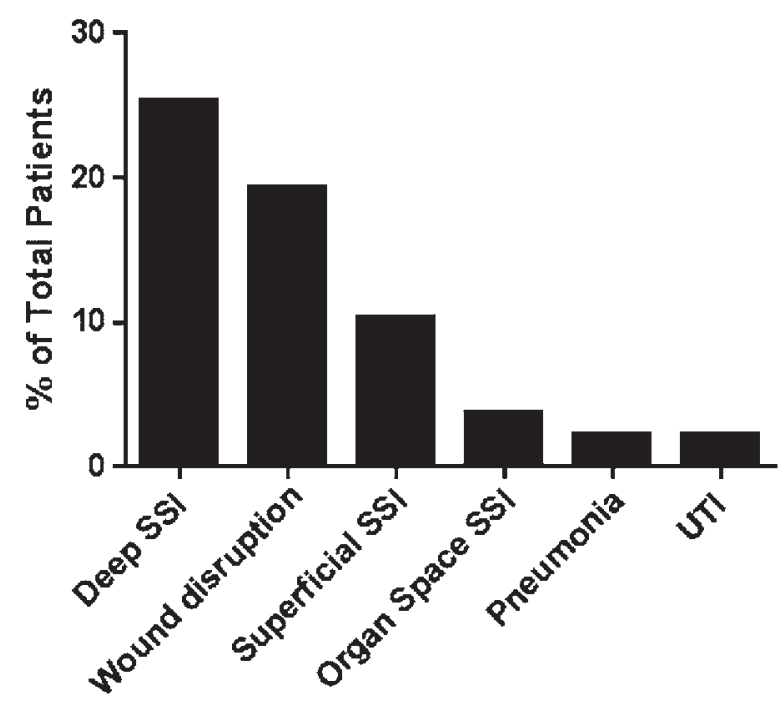

FIG. 1. Bar graph showing the reasons for unplanned readmissions in 134 patients. Postoperative systemic sepsis, pulmonary embolism, seizure, septic shock, and venous thromboembolism each accounted for $1 \%$ of unplanned readmissions.

female sex and pulmonary comorbidities (i.e., ventilator dependence, current pneumonia, asthma, cystic fibrosis, history of chronic lung disease, oxygen support, and structural pulmonary abnormalities) with ORs of 1.43 and 1.78 , respectively (Table 6).

\section{Discussion}

Understanding the risk factors and patient characteristics associated with unexpected outcomes has become increasingly important as health care agencies seek to implement quality control measures. Readmissions, reoperations, and complications can result in a significant burden on the health care system, with increased costs associated with patient morbidity. While a number of studies have reported on the short-term outcomes of pediatric patients undergoing spinal arthrodesis for spinal deformity or specific complications after spinal arthrodesis, few have investigated patient characteristics; comorbidities; and mortality, reoperation, and readmission rates in pediatric patients undergoing spinal arthrodesis for all indications. In this study, we used the ACS NSQIP database to identify pediatric patients undergoing spinal fusion surgeries for all indications to better characterize short-term outcomes in patients.

In this analysis, we were able to identify 4420 pediatric patients who underwent spinal arthrodesis with scoliosis and/or kyphoscoliosis being the most frequent indication for operation. We found that our analysis was comparable to those of other studies with similar populations. ${ }^{9}$ Furthermore, in our analysis the overall mortality was $0.14 \%$ with an overall complication rate of $9.0 \%$. The values obtained for overall morbidity and mortality are comparable to those reported in the literature for pediatric patients undergoing spinal fusion, particularly for spinal deformity. $3,4,8,16,19$ SSIs and wound dehiscence were the most common complications and also accounted for a majority of the indications for readmission and/or reoperations. Several studies have
TABLE 4. Reoperation indications and procedures $(n=159)$

\begin{tabular}{lc}
\hline \multicolumn{1}{c}{ Procedure/Indication } & No. of Patients (\%) \\
\hline Complex wound infection & $22(13.8)$ \\
\hline Incision \& drainage, deep abscess & $25(18.7)$ \\
\hline Hematoma/seroma/fluid collection & $13(8.2)$ \\
\hline Reinsertion of spinal fixation device & $11(6.9)$ \\
\hline Posterior arthrodesis & $11(6.9)$ \\
\hline Debridement of subcutaneous tissue & $9(5.7)$ \\
\hline Removal of instrumentation & $7(4.4)$ \\
\hline Debridement of bone, muscle, or fascia & $4(2.5)$ \\
\hline Exploration of spinal fusion & $4(2.5)$ \\
\hline Tube thoracostomy & $4(2.5)$ \\
\hline Debridement of open wound & $4(2.5)$ \\
\hline Closure of superficial wound dehiscence & $3(1.9)$ \\
\hline Tracheostomy & $3(1.9)$ \\
\hline Secondary closure of surgical wound & $2(1.3)$ \\
\hline Posterior segmental instrumentation & $2(1.3)$ \\
\hline Laminectomy of $>2$ thoracic vertebral segments & $2(1.3)$ \\
\hline Repair of dural/CSF leak/pseudomeningocele & $2(1.3)$ \\
w/ laminectomy & $31(19.5)$ \\
\hline Other &
\end{tabular}

also demonstrated that wound infections and wound dehiscence represent the most common complications following spinal arthrodesis in this population. ${ }^{11,15,16}$

We found that the unplanned readmission and reoperation rates were $3.96 \%$ and $3.6 \%$, respectively. Pugely et al. ${ }^{16}$ recently reported similar readmission $(3.94 \%)$ and reoperation $(3.74 \%)$ rates in patients undergoing arthrodesis for pediatric spinal deformities, and Minhas et al.$^{15}$ reported a 30-day readmission rate of $3.4 \%$ in pediatric patients in the NSQIP database who underwent surgical treatment of pediatric scoliosis. Li et al. ${ }^{12}$ also reported a 30-day reoperation rate of $2.1 \%$ in a single institution of patients undergoing fusion for spinal deformity. Jain et al., ${ }^{9}$ utilizing information from a single institution, reported a 90day readmission rate of $8.0 \%$, with a similar unplanned reoperation rate of $4 \%$ in patients undergoing spinal fusion for all indications. The unplanned readmission rates were higher in their cohort, which might be explained by the longer follow-up of their patients or the complexity of the cases seen at the tertiary institution. Notwithstanding, our reported values are comparable to those reported in the literature.

Pulmonary, CNS, gastrointestinal, and cardiac conditions were the most common comorbidities among this patient population. Univariate analysis revealed a number of significant factors associated with reoperation, including pulmonary comorbidities, esophageal/gastric/intestinal disease, CNS conditions, neuromuscular disorder, nutritional support, blood transfusion, acute renal failure, and wound complications. Interestingly, however, multivariate analysis demonstrated that female sex and the presence of pulmonary comorbidities significantly increased the odds of reoperation. The literature has shown that there is a higher rate of readmission and reoperation among patients with con- 
TABLE 5. Significant risk factors for reoperation (univariate analysis)

\begin{tabular}{lr}
\hline \multicolumn{1}{c}{ Risk Factor } & p Value \\
\hline Ventilator dependence & $<0.001$ \\
\hline Current pneumonia & $<0.001$ \\
\hline Oxygen support & $<0.001$ \\
\hline Structural pulmonary/airway abnormality & $<0.001$ \\
\hline Esophageal/gastric/intestinal disease & $<0.001$ \\
\hline CVA/stroke or traumatic/acquired brain injury with & $<0.001$ \\
$\quad$ resulting neurological deficit & \\
\hline Developmental delay/impaired cognitive status & $<0.001$ \\
\hline Seizure disorder & $<0.001$ \\
\hline Cerebral palsy & $<0.001$ \\
\hline Structural CNS abnormality & 0.002 \\
\hline Neuromuscular disorder & $<0.001$ \\
\hline Intraventricular hemorrhage & $<0.001$ \\
\hline Nutritional support & $<0.001$ \\
\hline Blood transfusion w/in 48 hrs prior to surgery & 0.032 \\
\hline Open wound & $<0.001$ \\
\hline Superficial SSI & $<0.001$ \\
\hline Deep incisional SSI & $<0.001$ \\
\hline Organ/space SSI & $<0.001$ \\
\hline Wound disruption & $<0.001$ \\
\hline Acute renal failure & $<0.001$ \\
\hline
\end{tabular}

CVA = cerebrovascular accident.

genital, genetic/syndromic, or neuromuscular scoliosis, as well as pulmonary complications. ${ }^{9,16}$ Respiratory complications represent a small percentage of the complications that can occur following spinal fusion, especially in the setting of the high prevalence of pulmonary comorbidities among pediatric patients who undergo such procedures. Sullivan et al. ${ }^{22}$ recently developed a model that demonstrated that preoperative pulmonary function increased the likelihood of patients requiring a higher level of postoperative care. Taken together, these results suggest that optimizing pulmonary function prior to a spinal arthrodesis procedure can potentially lead to decreased morbidity in this patient population. Female sex, on the other hand, has not been reported to affect the reoperation or readmission rate of spinal fusion patients. Females represented approximately $70 \%$ of the patients in our analysis, and, therefore, further investigation into this finding is warranted to ensure the best possible outcomes for these patients.

While the NSQIP database allows for an analysis of patients from multiple centers, there are nonetheless a number of limitations inherent in its use for this study. These include information bias with a short-term follow-up of 30 days, which constrains our assessment of long-term patient outcomes. Additionally, even though NSQIP provides a wealth of data on numerous surgical variables, there is a distinct lack of specific variables addressing spinal surgeries, such as the hardware-including screws, rods, plates and cages - used during arthrodesis and the exact number of levels fused, and the implications these have on patient outcomes. There is also the potential for sample bias giv-
TABLE 6. Significant risk factors for reoperation (multivariate analysis)

\begin{tabular}{lcl}
\hline \multicolumn{1}{c}{ Risk Factor } & p Value & \multicolumn{1}{c}{ OR $(95 \% \mathrm{Cl})$} \\
\hline Female sex & 0.035 & $1.43(1.03-2.0)$ \\
\hline Pulmonary comorbidities $^{*}$ & 0.002 & $1.8(1.2-2.6)$ \\
\hline
\end{tabular}

* Pulmonary comorbidities included ventilator dependence, current pneumonia, asthma, cystic fibrosis, history of chronic lung disease, oxygen support, and structural pulmonary abnormality.

en that the data collected may not be representative of all hospitals in the United States. Also, these comparisons are limited to available hospital characteristics and collected outcome measures. As such, there may be other unknown risk factors that better predict morbidity and mortality associated with spinal arthrodesis in the pediatric population.

\section{Conclusions}

Spinal arthrodesis is commonly performed in the pediatric population for pediatric spinal deformity and rarely for spinal tumors and trauma, among others. Understanding the patient factors that lead to undesired outcomes is essential for decreasing morbidity and mortality of pediatric patients undergoing these procedures. The use of the NSQIP database provides an avenue to assess patients from multiple centers. Our analysis revealed a $3.6 \%$ rate of unplanned reoperation, a $3.96 \%$ rate of unplanned readmission, and a $9.0 \%$ complication rate. Furthermore, the presence of pulmonary comorbidities and female sex represent significant risk factors for reoperation.

\section{Acknowledgments}

C. Rory Goodwin is a UNCF Merck Postdoctoral Fellow and has received an award from the Burroughs Wellcome Fund.

\section{References}

1. Basques BA, Bohl DD, Golinvaux NS, Smith BG, Grauer JN: Patient factors are associated with poor short-term outcomes after posterior fusion for adolescent idiopathic scoliosis. Clin Orthop Relat Res 473:286-294, 2015

2. Boakye M, Patil CG, Santarelli J, Ho C, Tian W, Lad SP: Cervical spondylotic myelopathy: complications and outcomes after spinal fusion. Neurosurgery 62:455-462, 2008

3. Carreon LY, Puno RM, Lenke LG, Richards BS, Sucato DJ, Emans JB, et al: Non-neurologic complications following surgery for adolescent idiopathic scoliosis. J Bone Joint Surg Am 89:2427-2432, 2007

4. Coe JD, Arlet V, Donaldson W, Berven S, Hanson DS, Mudiyam R, et al: Complications in spinal fusion for adolescent idiopathic scoliosis in the new millennium. A report of the Scoliosis Research Society Morbidity and Mortality Committee. Spine (Phila Pa 1976) 31:345-349, 2006

5. Croft LD, Pottinger JM, Chiang HY, Ziebold CS, Weinstein SL, Herwaldt LA: Risk factors for surgical site infections after pediatric spine operations. Spine (Phila Pa 1976) 40:E112-E119, 2015

6. Divecha HM, Siddique I, Breakwell LM, Millner PA: Complications in spinal deformity surgery in the United Kingdom: 5-year results of the annual British Scoliosis Society National Audit of Morbidity and Mortality. Eur Spine J 23 (Suppl 1):S55-S60, 2014 
7. Erfani MA, Pourabbas B, Nouraie H, Vadiee I, Vosoughi AR: Results of fusion and instrumentation of thoracic and lumbar vertebral fractures in children: a prospective ten-year study. Musculoskelet Surg 98:107-114, 2014

8. Fu KM, Smith JS, Polly DW, Ames CP, Berven SH, Perra JH, et al: Morbidity and mortality associated with spinal surgery in children: a review of the Scoliosis Research Society morbidity and mortality database. J Neurosurg Pediatr 7:37-41, 2011

9. Jain A, Karas DJ, Skolasky RL, Sponseller PD: Thromboembolic complications in children after spinal fusion surgery. Spine (Phila Pa 1976) 39:1325-1329, 2014

10. Khoshbin A, Lysenko M, Law P, Wright JG: Outcomes of infection following pediatric spinal fusion. Can J Surg 58:107-113, 2015

11. Kumar N, Tan JJ, Zaw AS, Lim JL, Wai KL, Malhotra R, et al: Evaluation of scoring systems and prognostic factors in patients with spinal metastases from nasopharyngeal carcinoma. Spine J 14:2946-2953, 2014

12. Li Z, Shen J, Qiu G, Yu H, Wang Y, Zhang J, et al: Unplanned reoperation within 30 days of fusion surgery for spinal deformity. PLoS One 9:e87172, 2014

13. Martin CT, Pugely AJ, Gao Y, Ilgenfritz RM, Weinstein SL: Incidence and risk factors for early wound complications after spinal arthrodesis in children: analysis of 30-day follow-up data from the ACS-NSQIP. Spine (Phila Pa 1976) 39:1463-1470, 2014

14. Martin CT, Pugely AJ, Gao Y, Weinstein SL: Causes and risk factors for 30-day unplanned readmissions after pediatric spinal deformity surgery. Spine (Phila Pa 1976) 40:238246, 2015

15. Minhas SV, Chow I, Feldman DS, Bosco J, Otsuka NY: A predictive risk index for 30-day readmissions following surgical treatment of pediatric scoliosis. J Pediatr Orthop 36:187-192, 2016

16. Pugely AJ, Martin CT, Gao Y, Ilgenfritz R, Weinstein SL: The incidence and risk factors for short-term morbidity and mortality in pediatric deformity spinal surgery: an analysis of the NSQIP pediatric database. Spine (Phila Pa 1976) 39:1225-1234, 2014

17. Pugely AJ, Martin CT, Gao Y, Mendoza-Lattes S: Causes and risk factors for 30-day unplanned readmissions after lumbar spine surgery. Spine (Phila Pa 1976) 39:761-768, 2014

18. Rajaee SS, Bae HW, Kanim LE, Delamarter RB: Spinal fusion in the United States: analysis of trends from 1998 to 2008. Spine (Phila Pa 1976) 37:67-76, 2012

19. Reames DL, Smith JS, Fu KM, Polly DW Jr, Ames CP, Berven SH, et al: Complications in the surgical treatment of 19,360 cases of pediatric scoliosis: a review of the Scoliosis Research Society Morbidity and Mortality database. Spine (Phila Pa 1976) 36:1484-1491, 2011

20. Schoenfeld AJ, Carey PA, Cleveland AW III, Bader JO, Bono
CM: Patient factors, comorbidities, and surgical characteristics that increase mortality and complication risk after spinal arthrodesis: a prognostic study based on 5,887 patients. Spine J 13:1171-1179, 2013

21. Schoenfeld AJ, Ochoa LM, Bader JO, Belmont PJ Jr: Risk factors for immediate postoperative complications and mortality following spine surgery: a study of 3475 patients from the National Surgical Quality Improvement Program. J Bone Joint Surg Am 93:1577-1582, 2011

22. Sullivan DJ, Primhak RA, Bevan C, Breakwell LM, Humphreys N: Complications in pediatric scoliosis surgery. Paediatr Anaesth 24:406-411, 2014

23. Taggart NW, Shaughnessy WJ, Stans AA, McIntosh AL, Driscoll DJ: Outcomes of spinal fusion in children with congenital heart disease. J Pediatr Orthop 30:670-675, 2010

24. Tauchi R, Imagama S, Ito Z, Ando K, Hirano K, Muramoto A, et al: Complications and outcomes of posterior fusion in children with atlantoaxial instability. Eur Spine J 21:13461352,2012

25. Yoshihara H, Yoneoka D: National trends in spinal fusion for pediatric patients with idiopathic scoliosis: demographics, blood transfusions, and in-hospital outcomes. Spine (Phila Pa 1976) 39:1144-1150, 2014

\section{Disclosures}

The authors report the following. Dr. Sponseller: clinical/research support for the current study from DePuy Synthes Spine and royalties from DePuy Synthes Spine and Globus. Dr. Sciubba: consultant for DePuy Synthes, Medtronic, Stryker, Globus, and K2M.

\section{Author Contributions}

Conception and design: Sciubba, Abu-Bonsrah, Goodwin, Ortega. Acquisition of data: Abu-Bonsrah, Goodwin, Ortega. Analysis and interpretation of data: Abu-Bonsrah, Goodwin, Ortega. Drafting the article: Sciubba, Abu-Bonsrah. Critically revising the article: all authors. Reviewed submitted version of manuscript: all authors. Approved the final version of the manuscript on behalf of all authors: Sciubba. Statistical analysis: Ortega. Administrative/ technical/material support: Sciubba, Abu-Bonsrah. Study supervision: Abu-Bonsrah.

\section{Supplemental Information Videos \\ Video Abstract. https://vimeo.com/233474294.}

\section{Correspondence}

Daniel Sciubba, Department of Neurosurgery, Johns Hopkins University School of Medicine, 600 North Wolfe St., Meyer 7-109, Baltimore, MD 21287. email: dsciubb1@jhmi.edu. 